\title{
Vent litt - og gjerne litt til
}

Et gammelt, opprinnelig latinsk ordtak sier at legens fornemste oppgave er å underholde pasienten mens naturen helbreder. Fortsatt er det viktig å beherske kunsten å avvente: den ekspektative terapi.

Legekunsten har vi hatt lenge, men fortsatt er livet forbausende kort, eller på latin: ars longa, vita brevis. Skuespilldikteren Molière, som for øvrig døde på scenen mens han spilte hovedrollen i sitt eget stykke Den innbilt syke, har sagt det slik: «Kunsten er lang, livet er kort, og legene formår med deres kunster og for deres egen fornøyelses skyld å forkorte det ytterligere.» Bak alt dette ligger det fremste bud i den antikke legekunsten: Nil nocere, eller: Man skal aldri skade noen. Nå som da kunne både legemidler og diverse inngrep være direkte skadelige for pasienten.

Som så mange andre kloke ord og holdninger fra eldre tider er denne viktige kunnskapen blitt mer eller mindre glemt. Altfor få leger har detaljkunnskap om betydningen av ekspektativ terapi, eller ekspektanse. I tidligere tider, da legen hadde mye mindre å hjelpe seg med enn i dag, var denne behandlingsformen noe av det helt sentrale i medisinen. Ikke minst var den ett av indremedisinens viktigste hjelpemidler, slik det blant annet fremkommer i følgende sitat (fritt etter professor Ernst Schjøtt-Rivers (1901-1982)): «På tross av intens og vedvarende ekspektativ terapi med puls, blodtrykk og EKG tatt hver time, ble pasienten stadig dårligere og døde utpå natten.»

Med dagens avanserte medisin kan et slikt utsagn virke både taktløst og støtende, og konsekvensen av å vente for lenge kan bli direkte farlig. Men det må balanseres mot to andre typer overdrivelser som kan være nesten like farlige: overdreven bruk av undersøkelser (jf. Ulysses-syndromet) og lidenskapen etter å behandle (jf. furor sanandi). Det aller farligste er når en gal diagnose blir intenst behandlet med feil terapi - det vil si at de to fenomenene forsterker hverandre.

Da er det viktig å kunne hente kloke ord fra vårt naboland. Stephan Rössner har i mange år vært en av Sveriges fremste fagpersoner innen livsstilssykdommer. I tillegg har han en for- tid som indremedisiner med et rikt forfatterskap og har vært redaktør i Svenska Läkaresällskapet. I denne artikkelen, som han skrev allerede i 1980 og som nå blir hentet frem i lyset igjen, viser han hvor viktig det kan være for pasienten at man av og til ser det hele litt an. I beste fall kan det virke direkte helbredende. Rössners artikkel er mer aktuell enn noensinne. Siden den gang har man delt den ekspektative terapien inn i to hovedformer: passiv og aktiv ekspektanse (1). Ved den førstnevnte bare venter man og ser. Ved den sistnevnte blir pasienten fulgt nøye opp, og skulle situasjonen forandre seg, griper man inn med én gang. Dersom kontakten mellom legen og pasienten er god, kan pasienten få resept på et relevant medikament, men bare bruke det hvis det blir nødvendig. I en nylig doktoravhandling har Sigurd Høye vist at man på den måten kan spare unødig bruk av antibiotika (2). Ved rygglidelser kan en slik holdning også praktiseres med stor suksess (1).

Glem ikke at hvis vi avsetter selveste naturen og dens helbredende kraft, så kan den hevne seg ganske grusomt. I verste fall går det ikke bare ut over pasienten, men det kan sette hele omsorgskulturen vår på spill.

\section{Ole Didrik Lærum}

ole.laerum@gades.uib.no

Ole Didrik Lærum er professor (adj.) ved Københavns Universitet og professor emeritus ved Universitetet i Bergen.

\footnotetext{
Litteratur

1. Nylenna M. Vond rygg - vente og se? Tidsskr Nor Lægeforen 1990; 110: 3093-4. 2. Høye S. Delaying prescribing - a feasible strategy to lower antibiotic use for respiratory tract infections in primary health care. Doktoravhandling. Oslo: Universitetet i Oslo, 2013.
}

\section{Exspektans - en bra och billig terapi som bör användas oftäre?}

\author{
Stephan Rössner
}

Stephan Rössner, docent och poliklinikchef vid Medicinska kliniken, Karolinska sjukhuset, S-104 01 Stockholm 60. Nordisk Medicin 95: 144-146, 1980.

Exspektans är en terapiform som är tämligen borglömd i läkarutbildningen. Ändå borde det bakom värje diagnostisk eller terapeutisk atgärd finnas ett övervägande om exspektans. Om inte undersökningen eller provet kan få en behandlingsmässig konsekvens eller medicinen gör patienten bättre bör läkaren avstå från åtgärden. Men det är naturligtvis aktiv - på kunskap grundad - exspektans läkaren i så fall skall tillämpa! 
- Patienten verkär spänd, blank i ögonen, lös i magen och har laboratoriegränsvärden för tyreotoxikos. Är svettningen ett uttryck för övertidspress eller en hormonrubbning? Vilken är vinsten med att behandla vägt mot vinsten att avvakta utvecklingen en tid? Vilket utrymme finns det för exspektans?

- Patienten är symtomfri, rädd for mediciner, men här en relativ hjärtvolym på over $600 \mathrm{ml} / \mathrm{m}^{2}$. Vad kan vinnas med hjärtstärkande medicinering? Har man rätt att ta risken av en uppseglande svikt om patienten är under kontroll?

- Sänkan är $50 \mathrm{~mm}$ per/timme tre veckor efter en infektion. Patienten mår bra men sänkan har bara krupit ner. Ligger det något annat bakom? Bör man utreda om orsaken är en tumör - eller vänta och se om inte allt normaliserar sig andå?

Tre vanliga situationer i kliniskt arbete, situationer som skilda läkare utifrån specialitetsinriktning, kunskap och personlighet kommer att bemästra på olika sätt. Några kommer att agera med diagnostik och farmaka i samtliga fall, andra kommer att avvakta utvecklingen. Att utreda och behandla är omfattande moment i den kliniska delen av vår läkarutbildning, att avvakta och invänta, dvs att ägna sig åt exspektans, är en åtgärd, som vi inte lärt oss använda lika väl. Denna artikel belyser några faktorer, som sammanhänger med tillämpningen av exspektans i kliniskt ärbete.

Exspektans är en behandlingsform som ofta har god effekt och måttliga biverkningar och som samtidigt är billig. Sannolikt har emellertid sjukvårdens explosionsartade utveckling av terapimetoder medfört att exspektans fått en mindre plats $i$ vår behandlingsarsenal än vad den egentligen förtjänar. Man måste emellertid skilja på olika former av exspektans.

\section{Passiv exspektans}

Patienten kan uppfatta exspektans som brist på intresse från läkaren. Detta är kanske orsaken till att många läkare, framför allt i början av sin bana, inte betraktar exspektans som ett förstahandsalternativ.

Passiv eller oavsiktlig exspektans innebär att patienten tillfrisknar medan papperskvarnarna mal. Det är inte helt ovanligt att sänkan blivit normal igen eller att smärtan forsvunnit när remissen väl kommit fram till «specialisten» och specialisten också fått tid att ta emot patienten. Denna form av exspektans är med rätta kritiserad. Patienten uppfattar handläggningen som nonchalans och brist på intresse - «ingen gjorde någonting». Den läkare som mottagit remissen och finner att patienten tillfrisknat konstaterar till sin belåtenhet att ytterligäre atgärder inte är nödvändiga. Han eller hon kan avskriva fallet utan att reflektera över vilka processer som ägt rum från sjukdomsdebuten till den första läkarkontakten och mellan denna och besöket hos specialisten.

Om den förste läkaren i sådana fall får feedback från specialisten kan han eller hon kanske vidga sina indikationer för exspektans. Om patienten stått på väntelista länge kvarstår emellertid frågan: Hade tillfrisknandet kunnat påskyndas och patientens lidande minskats med andra medicinska åtgärder tidigt under sjukdomsförloppet?

\section{Aktiv exspektans}

Betydligt viktigare är aktiv energisk exspektans. Det innebär att läkaren tar ett personligt ansvar och också klargör for patienten att tillståndet sannolikt är sådant att den bästa behandlingen är att avvakta. Ett sådant beslut innebär inte att läkaren är lättsinnig eller avstår från att engagera sig i fallet. Tvärtom. For att våga tillämpa aktiv exspektans måste läkaren ha gedigna kunskaper, god praktisk erfarenhet och en viss personlighet.

Patienten måste få klart för sig att det faktum att han eller hon lämnar mottagningen utan recept $i$ handen, röntgenstrålar i kroppen eller suturer i skinnet ingalunda är ett utslag av läkarens likgiltighet utan av en på erfarenhet och gediget medicinsk kunnande baserad bedömning. Grundtanken måste vara att det vid tillstånd som med stor sannolikhet spontant går i remission är onödigt att utsätta patienten för de risker, som praktiskt taget värje medicinsk behandling ändå kan innebära.

\section{Vem vågar vanta?}

Läkarens benägenhet att använda exspektans är självfallet beroende av vilket tillstånd det gäller och vilka andra behandlingsmöjligheter som står till buds. Neurologen, vars terapi-arsenal till stor del utgörs av sjukgymnastik, B-vitaminer och långvårdsremisser, använder sig flitigt av exspektans. Kirurgen däremot, som har så många operativa metoder att pröva, finner det otillständigt att hindra patienten från att komma i åtnjutande av alla kirurgins förträffligheter. För den nyutexaminerade invärtesmedicinaren med färmakologi som specialintresse kan det i början te sig självklart att behandla varje tillstånd av ohälsa med läkemedel - och ofta finns det ju då mycket att välja på.

\section{När är exspektans aktuellt?}

Vissa sjukdomar lämpar sig bättre än andra för exspektans. Det är osannolikt att exspektans kommer att få en framträdande plats när det gäller behandling av sepsis eller mjältruptur. Däremot används exspektans i dag ofta vid banala sjukdomstillstånd såsom luftvägsinfektioner, ömhet i muskler eller sömnsvårigheter.
Sannolikt skulle emellertid exspektans kunna användas i större omfattning också vid sjukdomar, där vi i dag i allmänhet väljer andra former av terapi. Det kan finnas anledning att påminna om de engelska undersökningar, som visar att vissa patienter med akut hjärtinfärkt kan vårdas i hemmet utan att komplikationsfrekvensen eller mortaliteten behöver öka (3).

Författarna menar att infarktavdelningens miljö kanske inte alltid är den bästa for patienten, och många antiarytmika som i dag ges (ofta i kombination) har så allvarliga biverkningar att dessa kanske överväger nyttan.

Den svenska Socialstyrelsens kommitté för läkemedelsinformation har nyligen publicerat ett symposium om farmakoterapi inom geriatriken (7). Där finns många tankeväckande rön om patienters användning av ordinerade läkemedel. Särskilt äldre patienter har i många fall svårt att ta sin medicin enligt läkarens ordination. Man vågar rent av påstå att endast en minoritet av dessa patienter tär sina mediciner som läkaren tänkt sig. Även unga människor sköter emellertid medicineringen bristfälligt, särskilt om deras sjukdom medför få eller lindriga symtom. En serie undersökningär från McMaster University i Kanada har t ex visat att det är mycket svårt att få asymtomatiska hypertoniker att regelbundet ta antihypertensiva trots att de fått utbildning och trots belöningssystem, träning i blodtrycksregistrering i hemmet etc (1). Det är uppenbart att vi inte får göra oss några illusioner om att patieterna verkligen använder alla de farmaka som läkare skriver ut. Resonemanget mynnar ut i två frågor:

- Hur ofta är exspektans ett fullgott alternativ till receptskrivning?

- Ger läkare tillräcklig information till patienter som med säkerhet kommer att ha nytta av läkemedel?

\section{Läkaren som terapeutikum}

Läkarens personlighet och attityder spelar självfallet en stor roll for hans eller hennes installning till exspektans. Det är ganska orimligt att begära att en nyutexaminerad läkare skall ha tillräckligt erfärenhet for att kunna väga riskerna med behandling mot chanserna för att aktiv exspektans skall ge resultat. Men även bland erfarna läkare varierar inställningen till exspektans. Den tekniskt händige läkaren ser ett sjukdomstillstånd som en störning i maskinen, och då är det naturligt att man analyserar möjligheterna att med olika medikamentella eller operativa åtgärder få maskinen att fungera normalt igen. Det finns dock kirurger vars stora talang är deras förmåga att avstå från operativa ingrepp i sådana fall där vinsterna kan förväntas bli begränsade. Med stigande alder och ökande erfarenhet genomgår säkert många läkemedelsförskrivande läkare en utveckling mot en viss terapinihilism. När 
högen av biverkningsrapporter växer, behandlingskostnaderna stiger och patienternas öppet visade missnöje tilltar är det allt svårare att ärgumentera for en färmakoterapi med begränsade effekter och potentiellt allvärliga biverkningär.

\section{Hur reagerar patienten?}

Patientens attityd är självfallet avgörande för exspektansens värde som behandlingsinstrument. Många människor som är sjuka avstår från att söka läkare därfor att de så att säga är experter på exspektans, dvs de är förvissade om att det mesta går över av sig självt. Andra som söker sjukvårdens hjalp kan inte acceptera exspektans som behandlingsalternativ, men en del av dem uppfattar diagnostiska procedurer som terapeutiska. Blodprovstagning eller lungröntgen kan sålunda vära suverän «behandling» vid t ex banala infektioner, i varje fall om patienterna inte är på det klara med att detta enbart är diagnostiska atgärder.

\section{Aktiv exspektans allt mer nödvändig}

Även om värdet av olika typer av halsoundersökningar ifrågasatts finns det en tendens att antalet screeningprocedurer ständigt ökar. Detta innebär att det kommer att ställas allt större krav på läkaren. Aktiv exspektans kommer att krävas oftare därför att man måste forhindra att symtomfria manniskor med serumkosmetiska skönhetsfel utsätts for omotiverade specialundersökningär eller annu värre behandling. Vi måste undvika att bidra till utbredningen av Odyssevs-syndromet (2). Detta innebär ju att en patient som söker för en viss åkomma utsätts for omotiverade undersökningar, som avslöjar bifynd, vilka föranleder behandling. Det uppstår ständigt nya diagnostiska och terapeutiska komplikationer och efter en lång slingrande vandring kommer patienten äntligen ut fran sjukvärden men är då märkt av läkemedelsexantem, frakturer efter fall från undersökningsbritsar, iatrogena blodskador etc medan det ursprungliga, relativt godartade tillståndet helt glömts bort under irrfärderna.

\section{Nya aspekter $\mathrm{i}$ utbildningen}

Henrik Wulffs bok «Rationell klinik» (6) borde vara obligatorisk läsning under den medicinska grundutbildningen. Det är nödvändigt att dagens medicine studerande får en mer nyanserad uppfattning om «vad som sker i det som synes ske». Det är viktigt att den kliniske farmakologens data om biologisk tillgänglighet kompletteras med uppgifter om hur få patienter som verkligen sköter sin medicinering enligt ordinationen - och om hur många läkare som verkligen forskriver läkemedel adekvat, dvs ger en rationell farmakoterapi.

Det är viktigt att vi också inom läkarutbildningen poangterar att många sjukdomar, även en del allvarliga, kan behandlas effek-

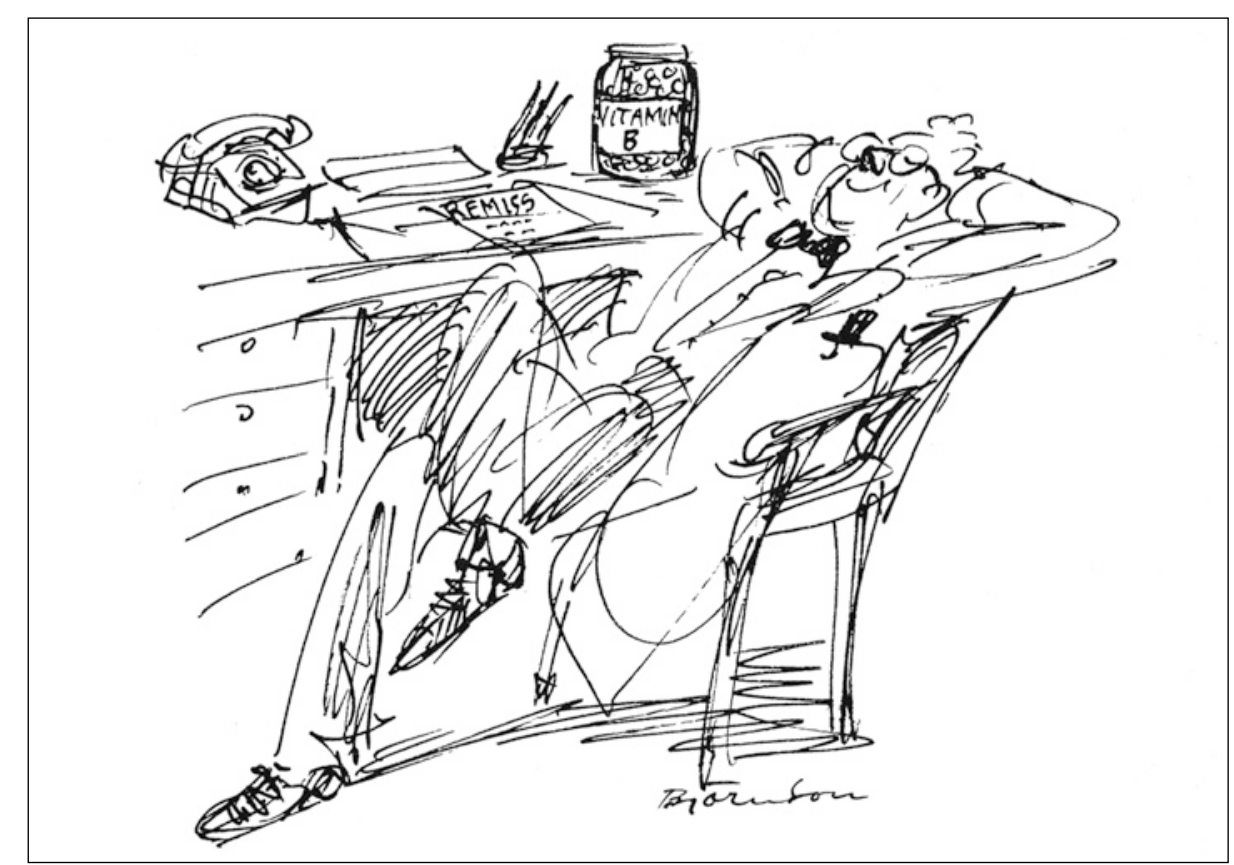

Neurologen, vars terapiarsenal till stor del utgörs av sjukgymnastik, B-vitaminer och långvårdsremisser, använder sig flittigt av expektans.... Teckningar: Erik Björnson, Stockholm

tivt genom att man avvaktar, observerar och registrerar men inte till värje pris prövar det ena terapeutiska alternativet efter det andra; ofta kan vi ju ändå inte utvärdera effekterna.

Sannolikt skulle exspektans kunna användas på ett bättre sätt än i dag inom sjukvården. Det är angeläget att läkare gör varandra uppmärksamma på att vissa av våra åtgärder faktiskt är en form av exspek-

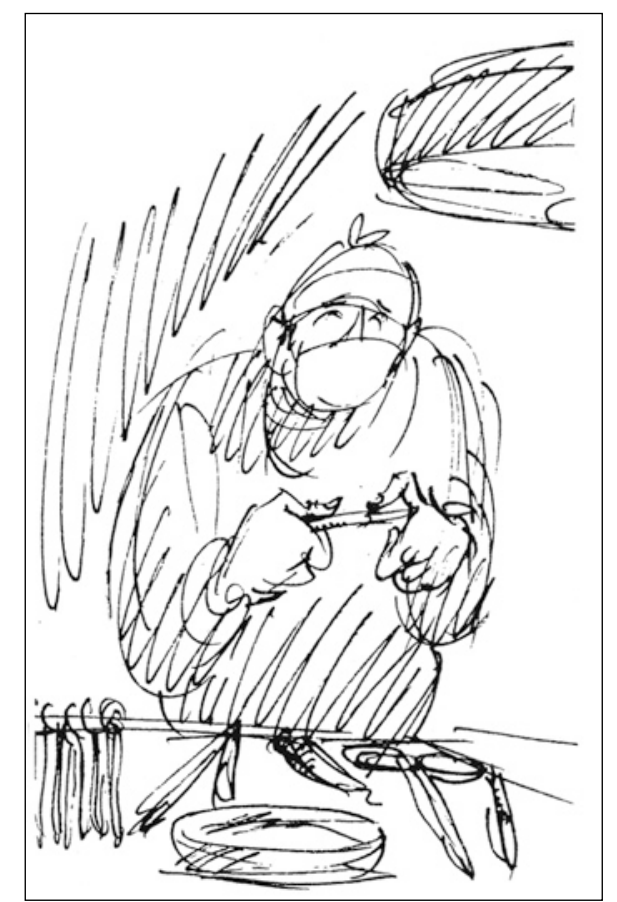

Kirurgen däremot, som har så många operativa metoder att pröva finner det otillständigt att hindra patienten från att komma i åtnjutande av kirurgins förträffligheter. tans och att detta är en etablerad behandlingsform, inte bara ett nonchalant sätt att behandla patienter och att ignorera symtom. Aktiv, energisk exspektans är något helt annat än glömska och brist på intressse för patientens problem.

Denna skillnad måste vi klargöra både för oss själva och för patienterna. Läkare säger ofta att patienterna förväntar sig ett recept när de söker läkare, men en färsk engelsk

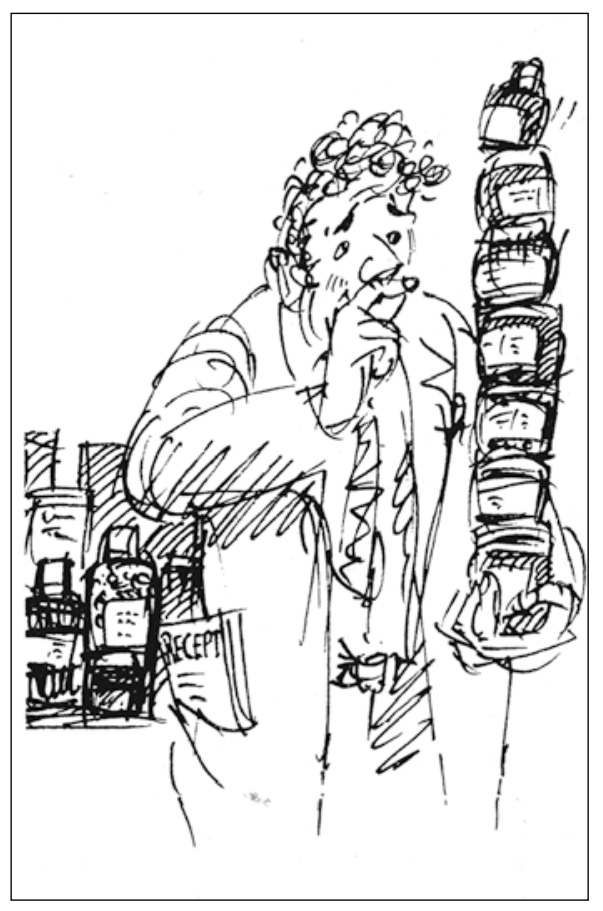

För invärtesmedicinaren med farmakologi som specialintresse kan det i början te sig självklart att behandla varje tillstånd av ohälsa med läkemedel och ofta finns det mycket att välja på... 
undersökning visar att läkarna ofta tror fel. Endast hälften av de patienter som söker läkare i England förväntar sig att få ett recept, men engelska läkare tror att sådana forväntningär finns hos 80 procent av patienterna (5). Uppenbarligen kan läkare tillämpa aktiv exspektans i atskilligt fler fall utan att göra patienterna besvikna!

\section{Exspektans när diagnosen är oklar} Frågan om exspektansens utnyttjande i vår terapi hänger till stor del samman med våra behov av diagnoser. Det känns otryggt att inte kunna klassificera ett sjukdomstillstånd (fastän kanske hälften av besöken i öppen vård inte kan klassificeras entydigt). Det verkar inkompetent att fortsätta på den diffusa linjen genom att inte föreslå någon specifik åtgärd. «If you cannot make a diagnosis, at least make a decision» är ett klokt tankesätt, som gäller den diagnostiska delen av patientens kontakt med sin läkare. For terapiavsnittet av patient-läkar-kontakten kan man tänka sig ett annat anglosaxiskt uttryck: «When in doubt, don't».

Ett viktigt skäl till att exspektans är en betydelsefull behandlingsform är att många sjukdomär har sina non-disease (antisjuka) motsvårigheter. Meador skrev 1965 en essä «The Art and Science of Non-disease» (4). Där framförde han hypotesen, att inte bara sjukdomar utan även frånväro av sjukdom kan klassificeras. Avsaknad av sjukdom behöver inte betyda hälsa utan kan enligt Meador tänkas förekomma i följande grupper
1. Imitationer. Vem har inte letat efter feokromocytom hos nervosa, svettiga individer med hjärtklappning och röda kinder eller beställt steroidanalyser på feta, håriga kvinnor för att kanska finna $\mathrm{Mb}$ Cushing?

2. Gränsvärdestolkning. Oroliga människor med tyroideahormoner i övre gränsområdet behöver ändå inte ha tyreotoxikos.

3. Normal variation. Kortvuxenhet hos en individ med korta foräldrar behöver ingalunda vara dvärgväxt.

4. Felaktiva laboratorie-svar. Det har upprepade gånger framhållits, att laboratorieanalyser endast är hjälpmedel med oundvikliga felkällor, och att den terapeutiska konsekvensen måste baseras på en bedömning av patienten som helhet.

5. Övertolkning av undersökningsfynd. Röntgenfynd, som inte kan bekräftas vid operation; funktionella systoliska blåsljud, som inte betyder stenos är exempel på övertolkning.

De ovan nämnda situationerna, där man till många reella sjukdomar kan finna motsvarande non-diseaseformer, borde vära en viktig tankestalläre. Ty om vissa sjukdomar primärt skall behandlas med exspektans är det väl uppenbart, att deras non-ekvivalenter inte heller skall behandlas. Och under den osäkra period, när man inte vet, kan det vära nyttigt att avvakta.

Non-disease är, hävder Meador, dessutom ofta vanligare än själva sjukdomen.

Läkaren är rädd för att betrakta patienten som frisk. «En frisk patient är en som inte är tillräckligt noga undersökt ... » I den utredningskarusell, som följer, känns det sedan futtigt att inte fullfölja de medicinska insatserna med någon terapi av mera påtagligt slag.

Igenkännandet av non-disease-systemet, som löper parallellt med vår gängse klassifikation av sjukdomar, måste också läras in under läkarutbildningen. Vetskapen om systemets betydelse borde göra oss alla medvetna om svårigheten att ha ett säkert diagnostiskt fundament inför det terapeutiska handlandet. Det borde stämma till eftertanke och ge exspektansen ett ökat utrymme.

\footnotetext{
Litteratur

1. Haynes, R B, Sackett, D L, Gibson, E S, Taylor D W. Hackett, B C, Roberts, R S \& Johnson, A L: Improvement of medication compliance in uncontrolled hypertension. Lancet i: 1265-1268, 1976.

2. Lærum O D: Ulysses-syndromet. Helseproblemer hos patienter med non-disease. Nord Med 91. 205-207, 1976

3. Mather, H G, Morgan, D C, Peärson, N G, Read, K L Q, Shaw, O B Steed, G R, Thorne, M G, Lawrence, C J \& Riley, IS: Myocardial infarction: a comparison between home and hospital care for patients. Br Med J 1: 925,1976.

4. Meador, CK. The art and science of non-disease New Eng J Med 272: 92, 1965.

5. Thomas, K B: The consultation and the therapeutic illusion. Br Med J 1: 1327, 1978.

6. Wulff, W: Rational diagnosis and treatment. 1 ed Blackwell Scientific Publication Oxford, London, Edinburgh, Melbourne, 1976.

7. Farmakoterapi inom geriatriken. Socialstyrelsens kommitté för läkemedelsinformation 1979
}

\section{SYK - SKADET - UFØR}

\author{
Vi har spesialisert oss innen trygderett \\ og personskadeerstatning.
}

\section{Vi kan tilby Deres pasienter inntil} 1 time gratis rådgivning innenfor de nevnte saksområder.

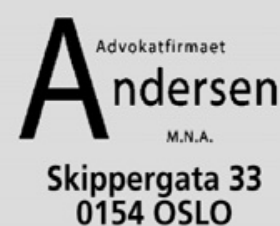

Telefon: + 4722419555

Telefaks: + 4722420163

Email: anders.andersen@aajuss.no

Webadresse: www.aajuss.no

\section{Kostnadsfri inkasso:}

1. Ingen etableringsgebyrer eller årsavgifter.

2. Du beholder ALLTID hele hovedstol uansett når vi løser saken.

3. Du beholder $50 \%$ av rentene selv.

4. Ingen påslag ved rettslig inkasso.

5. Ikke løsbare saker belastes ikke (ved f.eks konkurs/ gjeldsordning)

6. Gunstig inndekningsrekkefølge.

7. Ved feil kan oppdrag trekkes kostnadsfritt.

8. Fast saksbehandler og kundekontakt.

9. Gratis håndtering av gjeldsordning, dødsbo og konkursbo.

10. Gratis purreservice.

11. Du får svar 7 dager i uken, vi jobber aktivt med å løse en sak fra dag en ved bruk av post, e-post og telefon.

12. Vi utbetaler til våre kreditorer en gang i uken

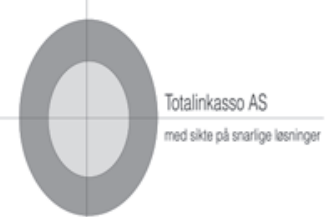

Vi er godkjent av

Finanstilsynet for å drive inkassovirksomhet, og bestreber oss på å behandle skyldnere med respekt, og innenfor god inkassoskikk. Siden vi er et lite inkassobyrå kan vi ta raske beslutninger for å få til en løsning.
WWW.TOTALINKASSO.NO

\section{Epost: post@totalinkasso.no・Telefon: 41251648}

Via våre samarbeidspartnere over hele landet, kan vi også gi et godt tilbud på regnskapsføring. 